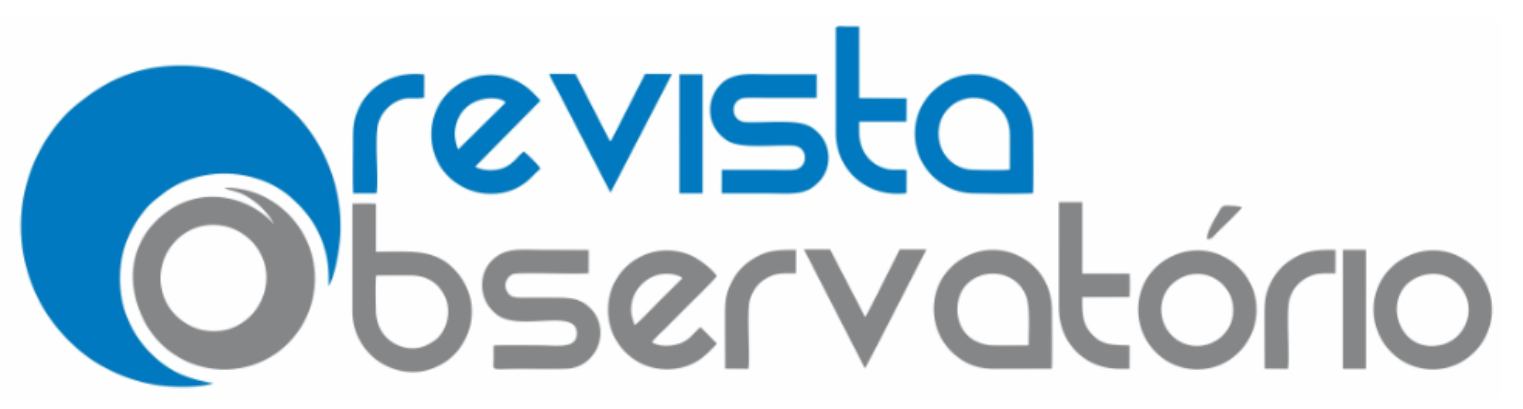

ISSN n² 2447-4266

Vol. 5, n. 4, Julho-Setembro. 2019

DOI: http://dx.doi.org/10.20873/uft.2447-4266.2017v5n4p27

\title{
EXTENSÃO EM JORNALISMO E COMUNICAÇÃO: diálogos por e entre saberes
}

Do tripé constitutivo da universidade, a extensão é o que menos tem publicações específicas, congressos e livros a ela dedicados. A partir da relação com o ensino e a pesquisa, essa constatação indica uma necessidade de mais destaque para os relatos extensionistas, focados no atendimento à comunidade e na difusão para o público - além dos pares da academia - do conhecimento produzido nos grupos científicos, nos laboratórios, nas salas de aula e nas interações com a sociedade. Dessa forma, o dossiê temático é dedicado ao tema EXTENSÃO EM JORNALISMO E COMUNICAÇÃO: diálogos por e entre saberes.

Este dossiê da Revista Observatório, que reúne onze artigos, com produção de instituições diferentes, públicas e privadas, busca contribuir para que a extensão também tenha publicações qualificadas e as experiências possam, não só ser registradas, como também servir de base para outras ações. No campo da Comunicação e do Jornalismo, sobre os quais versam os referidos textos, a extensão pode ter ainda papel mais importante no sentido de garantir que o acesso à informação de qualidade, com diversidade e de modo democrático, possa ser garantido e contribuir com o desenvolvimento social. Nesse sentido, filiamo-nos e fazemos lembrança ao pensamento do sociólogo Herbert de Souza (1935-1997), Betinho, ao afirmar que o termômetro que mostra a democracia no país mensura também a participação das pessoas na comunicação. As experiências deste dossiê mostram como as universidades podem dar sua contribuição ao debate e à construção de uma comunicação mais inclusiva.

À medida que as ações de extensão, por força da bem-vinda medida de curricularização prevista pelo Ministério da Educação (MEC), tornarem-se obrigatórias, serão necessários muitos dossiês e materiais como este, que ajudem a construir conhecimento, compartilhem experiências e indiquem - ao mesmo tempo em que são construídas conjuntamente - metodologias adequadas para as atividades e para a avaliação de resultados. Importante considerar que a inserção de 


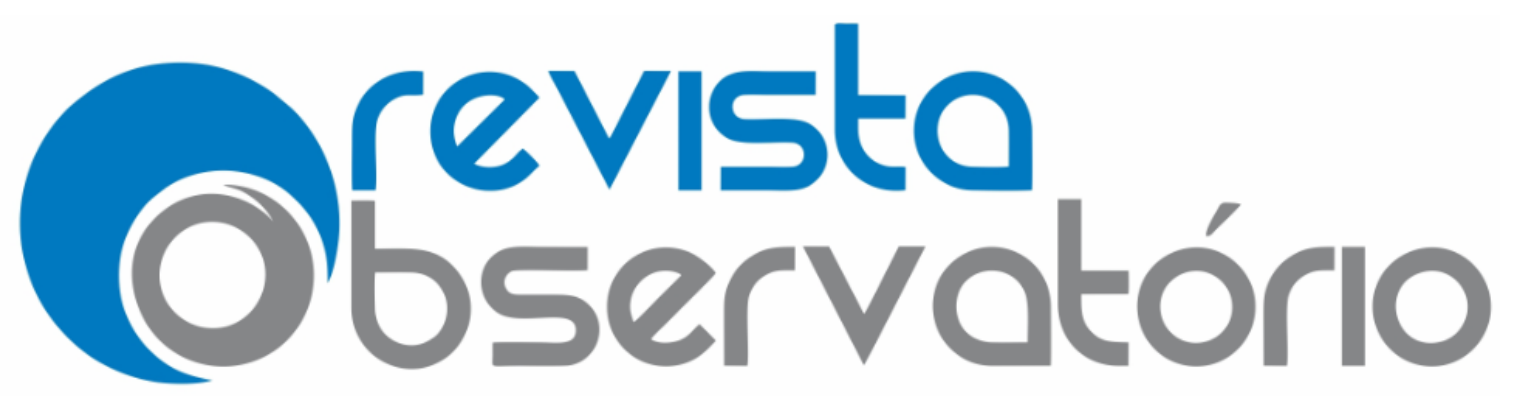

ISSN n² 2447-4266

Vol. 5, n. 4, Julho-Setembro. 2019

DOI: http://dx.doi.org/10.20873/uft.2447-4266.2017v5n4p27

créditos de extensão nos currículos de graduação é uma necessidade urgente para permitir aos jovens estudantes uma ampliação dos espaços de aprendizagem e de socialização do conhecimento (BRASIL, 2013; FORPROEX, 2012). A extensão universitária é, ao mesmo tempo, pesquisa e ensino, trocando saberes com os envolvidos e realimentando o cotidiano dos laboratórios e salas de aula, o que permite aos estudantes um encantamento profissional com a realidade que vão vivenciar ao se tornarem profissionais (CANCLINI, 2001; YÚDICE, 2004).

Algumas das experiências deste dossiê são oriundas de trabalhos que nasceram em disciplinas de cursos de Jornalismo e, em alguns casos, compartilhadas com outras áreas da Comunicação. É o caso dos cinco primeiros textos. No primeiro deles, de autoria de Valci Zuculoto, Juliana Gobbi Betti, Beatriz Hammes Clasen e Gabriel Gentile de Aguiar, é descrita a cobertura realizada pela rádio da UFSC das eleições municipais em Florianópolis (SC), em 2016 (ZUCULOTO et al., 2019).

No segundo, a experiência narra a implantação de uma rádio, por alunos e professores da Universidade do Estado da Bahia (Uneb), levando informação ao Semiárido Nordestino. As autoras, Fabíola Moura Reis Santos e Maria Jamile Amaral Alves, contam como a experiência agrega conhecimento não só aos alunos envolvidos, mas, principalmente, oferece um novo jeito de se informar, mais comunitário e ligado à cultura local (ALVES; SANTOS, 2019).

Do Nordeste, vem também a experiência descrita por Fernando Firmino da Silva, Ana Flávia Nóbrega Araújo e Emanuelle de Carvalho Rocha, da Universidade Estadual da Paraíba (UEPB). O projeto de extensão diz respeito à produção de conteúdo noticioso e convergente para os festejos tradicionais de Campina Grande durante o mês de junho, integrando formação, comunicação e pertencimento comunitário (SILVA et al., 2019).

A experiência de produção jornalística, de caráter comunitário, focando a cultura popular paraibana também é tema do trabalho de André Luiz Piva de Carvalho, da Universidade Federal da Paraíba (UFPB), que, além do trabalho informativo, é responsável pela produção de um inventário de artes e cultura regional (CARVALHO, 2019).

Fechando esse primeiro conjunto de artigos, há o texto sobre a experiência de criar um veículo de comunicação focado no acompanhamento das ações legislativas de Frutal, em Minas Gerais, conforme relatam os autores Karol Natasha Lourenço Castanheira, Daniel Bruno Fernandes 


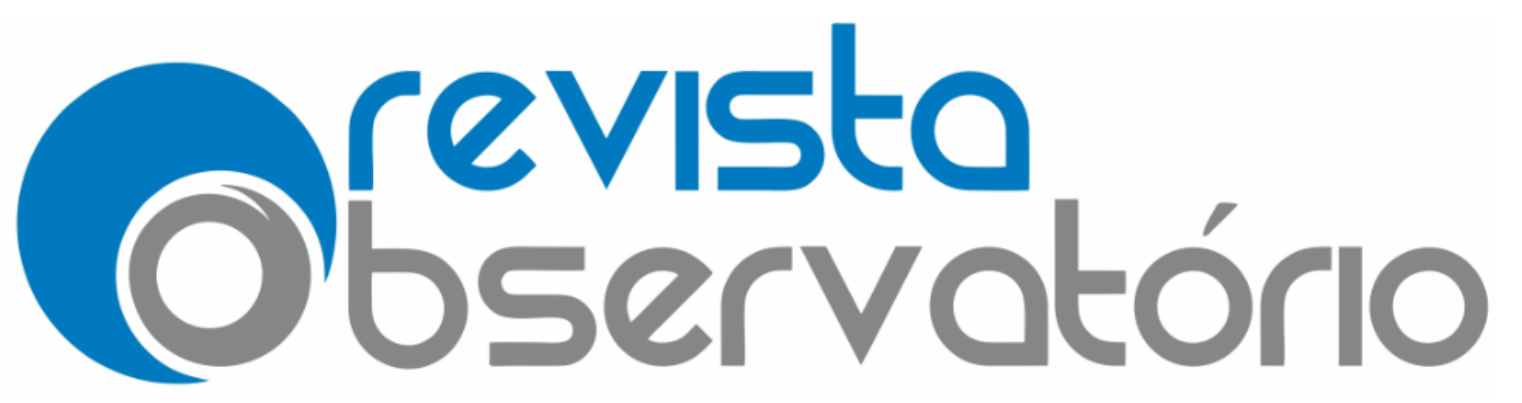

ISSN n²447-4266

Vol. 5, n. 4, Julho-Setembro. 2019

DOI: http://dx.doi.org/10.20873/uft.2447-4266.2017v5n4p27

Conrado e Edson Vieira Bueno Júnior. Essa atividade envolve duas instituições de Ensino Superior: a Universidade Estadual de Minas Gerais (UEMG) e o Instituto Federal do mesmo estado (IFMG) (CASTANHEIRA et al., 2019).

Na sequência, o texto de Alberto Marques e Alan Rios relata como as atividades de extensão podem ser fomentadas por projetos institucionais ou governamentais, como é o caso do Projeto Rondon, do Ministério da Defesa. A ação desenvolvida com alunos da Universidade Católica de Brasília (UCB) teve lugar em municípios do Tocantins e do Maranhão (SILVA; RIOS, 2019).

O texto escrito por Pablo Laignier, da Universidade Estácio de Sá (Unesa), conta uma experiência que envolveu cinema e jornalismo, agregando público interno e externo à instituição de ensino, ao oferecer lazer, possibilidade de discussão e de relacionamento entre academia e comunidade (SOUZA, 2019).

O oitavo texto do dossiê, assinado por Patrícia Paixão, narra uma experiência que sobrevive independente do vínculo com uma instituição de ensino e oferece um importante registro para a história do Jornalismo e para a prática da reportagem no Brasil, ao entrevistar e registrar em livros alguns dos mais destacados repórteres do País (MARCOS, 2019).

O nono texto demonstra a relação salutar existente entre a extensão e a pesquisa, ao apresentar o trabalho desenvolvido na Universidade de Sorocaba (Uniso) por Leila Gapy, Mara Rovida, Monica Martinez, Paulo Celso da Silva, que, ainda em andamento, já culminou com a produção de 20 narrativas audiovisuais sobre a trajetória pessoal e profissional de sorocabanos, constituindo um acervo de memórias e histórias à margem dos relatos oficiais e tradicionais (GAPY et al., 2019).

Duílio Fabbri Júnior e Fabiano Ormaneze, dois dos organizadores deste dossiê, mostram como a extensão universitária pode contribuir com a formação continuada dos jornalistas e outros profissionais da comunicação. Para isso, os autores analisam a experiência de um curso oferecido pela Escola de Extensão da Universidade Estadual de Campinas (Extecamp-Unicamp), cujo foco foram as questões relacionadas a gênero na imprensa, possibilitando reflexões e novos instrumentos aos profissionais da área (FABBRI JUNIOR; ORMANEZE, 2019). 


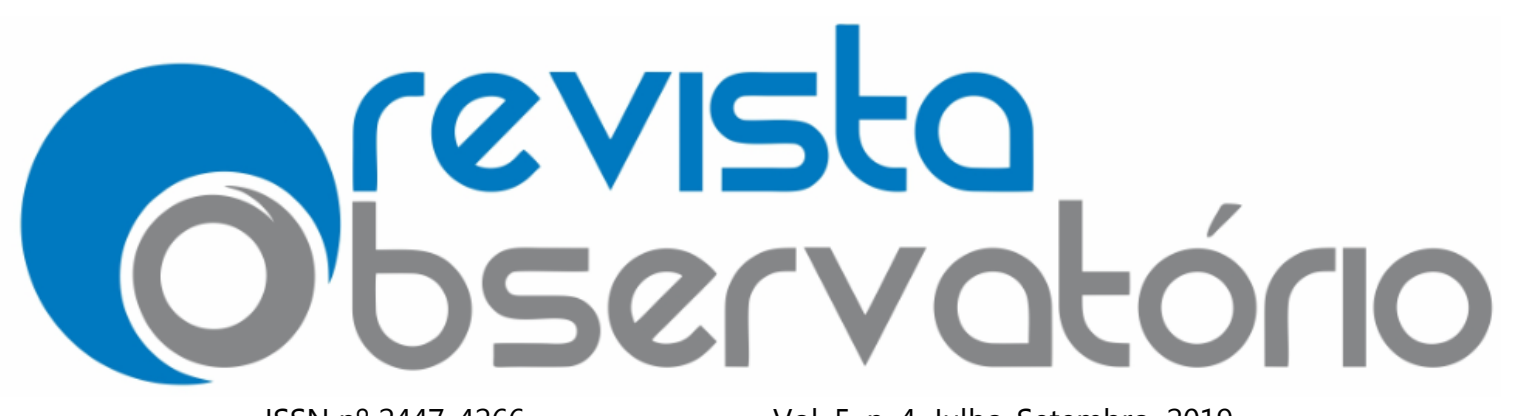

ISSN n² 2447-4266

Vol. 5, n. 4, Julho-Setembro. 2019

DOI: http://dx.doi.org/10.20873/uft.2447-4266.2017v5n4p27

Ainda na linha da extensão como estratégia de formação continuada para a comunidade, o texto de Orlando Berti, da Universidade Estadual do Piauí (Uespi), fecha este dossiê ao descrever a experiência de duas edições de um curso que relaciona fotografia, feminismo(s) e militância, na Capital e no Sertão do Estado (BERTI, 2019).

Com experiências tão diversas e dialógicas, que, de algum modo, envolveram todas as regiões do País, esperamos que este dossiê contribua com reflexões e perspectivas sobre a extensão no Brasil e ofereça subsídios para novas experiências de sucesso.

Em TEMAS LIVRES, iniciamos com o artigo JORNALISMO E AFETOS NA EXPERIÊNCIA TRANSMÍDIA DO MOVIMENTO AMBIENTAL de Katarini Giroldo Miguel e Mylena Fraiha Machado partem da hipótese de que o movimento ambiental, ao assumir as mudanças tecnológicas da contemporaneidade, tem se apropriado das Tecnologias da Informação e Comunicação e dos novos formatos e gêneros narrativos que elas possibilitam. Com isso, produzem um tipo de jornalismo ambiental engajado, e que comporta os problemas socioambientais com mais profundidade e empatia, em um contexto de experiências tecnológicas como as narrativas transmidiáticas, as longforms, a realidade virtual, a gamificação (MICHEL; MACHADO, 2019).

O artigo CIBERESPAÇO, MULTITAREFAS E ATENÇÃO: Breve revisão bibliográfica de Luiz Fernando Corcini e Alvino Moser tratam como o ciberespaço, com a interligação de todos os dispositivos tecnológicos potencializou o crescimento do hábito multitarefa. Primeiro, apresentase os conceitos de cibercultura e de ciberespaço, segundo Pierre Lévy. Em seguida, mostra-se como o ciberespaço, por ser a interconexão global de computadores e outros dispositivos, possibilita aos usuários se conectarem em várias redes e fazerem várias tarefas ao mesmo tempo e assim potencializa a emergência dos indivíduos multitarefas ou multitaskers. (CORCINI; MOSER, 2019)

O artigo CONVERGÊNCIA JORNALÍSTICA: Uma revisão de métodos das Dissertações e Teses do banco da Capes (2012-2017) de André Luiz Lucas da Luz e Ivan Bomfim revisam os métodos científicos utilizados em dissertações e teses disponíveis no banco de publicações da Coordenação de Aperfeiçoamento de Pessoal de Nível Superior (Capes), que possuam a ótica da convergência jornalística. O levantamento demonstra predominâncias de técnicas, perspectivas 


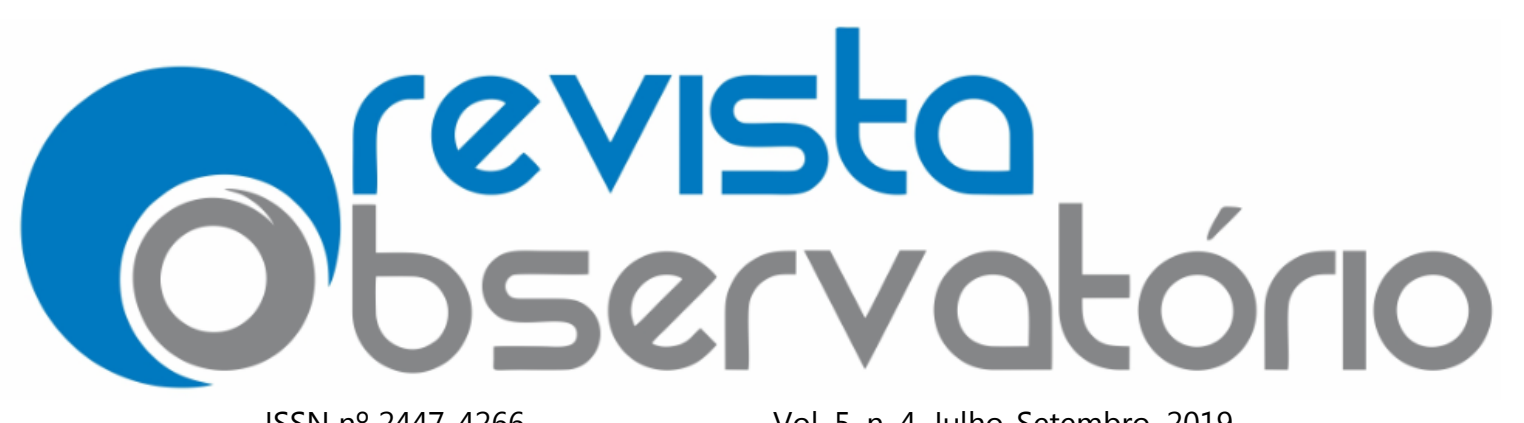

ISSN n²447-4266

Vol. 5, n. 4, Julho-Setembro. 2019

DOI: http://dx.doi.org/10.20873/uft.2447-4266.2017v5n4p27

teóricas e temáticas em um resultado de pesquisas que corresponde aos anos de 2012 a 2017 (LUZ; BOMFIM, 2019).

Já no artigo JORNALISMO NOS LIMITES DA LIBERDADE: cobertura da imprensa sobre os casos dos religiosos acusados de praticar atividades subversivas durante o regime militar de Robson Dias, Eliane Muniz Lacerda e Victor Márcio Laus Reis Gomes analisam a cobertura da imprensa durante a ditadura militar no Brasil, com base em cinco casos de religiosos acusados pelo regime de praticar atividades subversivas. A análise corresponde ao período histórico de 1968 a 1977. Os cinco casos em estudo foram selecionados entre dezoito noticiados pela imprensa neste mesmo período. A divulgação feita pelos jornais Folha de S. Paulo, Jornal do Brasil, O Estado de $S$. Paulo e $O$ Globo totalizou 53 notícias. A cobertura da imprensa é analisada a partir da perspectiva de abordagem da Hipótese da Agenda-setting e do enquadramento dado às notícias (DIAS et al., 2019).

O artigo NEM INFERNO, NEM PARAÍSO: Esfera pública e a construção de um conceito de Amazônia (1930-1937) de Luís Francisco Munaro apresenta a contribuição literária de um grupo de intelectuais manauaras durante os anos de construção nacional no Governo Provisório e no Governo Constitucional de Getúlio Vargas (1930-1937). Foram selecionados seis nomes que participaram mais ativamente da esfera pública amazônica: Aurélio Pinheiro, Anísio Jobim, Araújo Lima, Carlos Mesquita, Ramayana Chevalier e Arhur Reis, todos homens de imprensa com ativo trânsito nos jornais e produção de libros (MUNARO, 2019).

Em VALORES-NOTÍCIA E INTERNET: Um estudo exploratório sobre as notícias mais acessadas do portal aRede de Cintia Xavier e Afonso Verner apresentam as notícias mais acessadas (visualizadas) do portal aRede de fevereiro de 2014 a agosto de 2015. O portal está no ar desde de dezembro de 2013 e promete uma "cobertura 24 horas das notícias de Ponta Grossa e dos Campos Gerais" - o principal eixo de notícias refere-se ao setor policial e de segurança. Nesse sentido, o texto apresenta uma reflexão inicial sobre os valores-notícia e critérios de noticiabilidade, o uso desses aspectos e a nova configuração do processo de produção da notícia na era da internet (XAVIER; VERNER, 2019).

O artigo DA COMUNICAÇÃO NÃO-VIOLENTA À CULTURA DE PAZ: círculos, narrativas e contribuições de Cristovao Domingos de Almeida, Simone Barros Oliveira e Letícia Souza Brum 


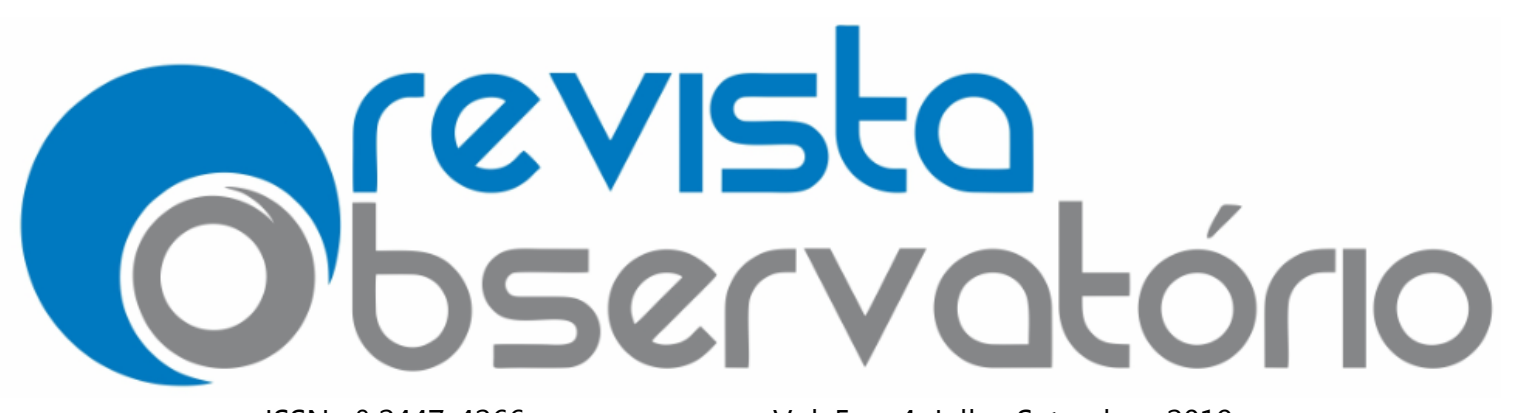

ISSN n²447-4266

Vol. 5, n. 4, Julho-Setembro. 2019

DOI: http://dx.doi.org/10.20873/uft.2447-4266.2017v5n4p27

Investigam a possibilidade de uma prática não ideológica que se aproxima da Cultura de paz. Essa possibilidade se materializa através dos círculos de construção de Paz que juntamente com o os fundamentos teóricos da comunicação não-violenta e dos estudos de paz, alicerçam e tornam palpável a transformação de uma cultura tradicional para uma cultura de Paz (ALMEIDA et al., 2019).

O artigo MEIOS DE COMUNICAÇÃO: Extensão e Alienação de Patricio Dugnani analisa o uso das redes sociais, em foco, como ambiente de debates, que acaba por apresentar, não um discurso crítico, mas simplesmente o senso comum, denominado por Roland Barthes como doxa. Procura-se entender o uso paradoxal da comunicação, que, se por um lado, tem a função de estender a percepção humana, ampliando, assim, a consciência de mundo, por outro, parece levar esse mesmo humano a um ambiente de incompreensão e de intolerancia (DUGNANI, 2019).

Já no artigo COMUNICAÇÃO INTEGRADA EM UMA UNIVERSIDADE PÚBLICA: um modelo para análise situacional na perspectiva da teoria da comunicação integrada e da análise de redes sociais de Ana Emilia Galvão Holanda e Pâmela de Medeiros Brandão apresentam um modelo para análise situacional da comunicação integrada em uma Universidade pública fundamentado na perspectiva da Teoria da Comunicação Organizacional Integrada e da Análise de Redes Sociais. O modelo proposto comporta conceitos, finalidades e procedimentos para o aprimoramento dos processos da comunicação organizacional deste tipo de organização pública (HOLANDA; BRANDÃO, 2019).

O artigo A COBERTURA DO BNDES NOS GOVERNOS FHC E LULA: bases ortodoxas nas narrativas sobre privatizações e PAC de Thaize Ferreira Macêdo Rosa e Antonio José Pedroso analisam as relações entre economia e mídia, de forma a demonstrar suas particularidades e afinidades através da análise sobre o tratamento da imprensa brasileira ao Banco Nacional do Desenvolvimento Econômico e Social (BNDES). No estudo foi aplicada a análise de enquadramento nas matérias sobre o BNDES que constavam nas editorias de dos jornais Folha de São Paulo, $O$ Estado de São Paulo e O Globo nos anos 1996 a 1998, para representar o período FHC, e 2007 a 2009, do governo Lula (ROSA; PEDROSO NETO, 2019).

O artigo METODOLOGIAS DE DIFUSÃO DO CONHECIMENTO NO ENSINO SUPERIOR EAD: contribuições dos MOOCS de Ana Cristina de Mendonça Santos, Maria Teresa Ribeiro 


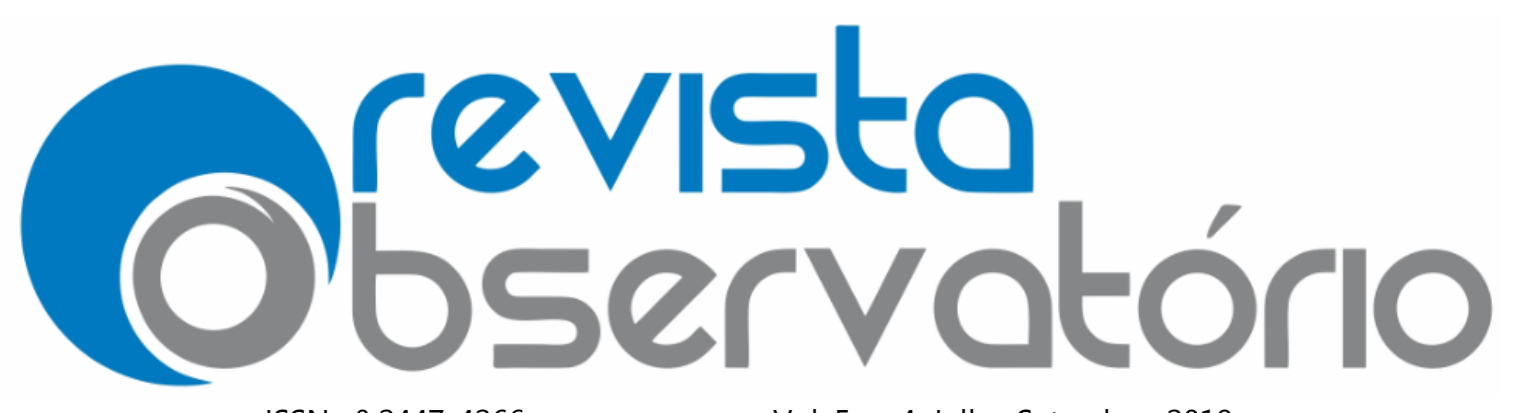

ISSN n²447-4266

Vol. 5, n. 4, Julho-Setembro. 2019

DOI: http://dx.doi.org/10.20873/uft.2447-4266.2017v5n4p27

Pêssoa e Maria de Fatima Hanaque Campos apresentam uma pesquisa realizada durante a realização do Estágio Doutoral Sanduíche na Universidade de Coimbra/Portugal, sobres as contribuições das metodologias utilizadas nos MOOCs para o processo de difusão do conhecimento no Ensino Superior EAD. Tem como objetivo geral investigar as contribuições dos MOOCS operacionalizados em três Universidades de Portugal para a construção de uma metodologia de difusão de conhecimento em ambientes virtuais de aprendizagens (SANTOS; PÊSSOA, 2019).

\section{Em TECNOLOGIAS DIGITAIS DE INFORMAÇÃO E COMUNICAÇÃO COMO RECURSO DE} MEDIAÇÃo PEDAGÓGICA de Marluce Zacariotti e José Luis dos Santos Sousa buscaram diagnosticar a realidade das escolas públicas de Grajaú, Maranhão, quanto ao uso das tecnologias digitais de informação e comunicação (TDIC) no ensino de Ciências. O objetivo foi levantar como as TDIC estão sendo utilizadas nas escolas, pelos professores de Ciências (ZACARIOTTI; SOUSA, 2019).

O artigo APRENDER “COM” A TECNOLOGIA: O uso do Facebook no processo de aprendizagem e interação de curso online de Elaine Jesus Alves e Bento Duarte da Silva discutem o papel das redes sociais nos contextos educativos presenciais e mediados por tecnologias. Neste sentido, o texto apresenta a experiência do uso da rede social Facebook no processo de aprendizagem entre os servidores da Universidade Federal do Tocantins alunos do curso Integração do servidor na UFT 2016 (ALVES; SILVA, 2019).

O artigo ORFANDADE EMOCIONAL: uma herança refletida nas salas de aula de Wesley da Silva Santos e Patricia Medina tratam de questões relacionadas às necessidades de desenvolvimento dos aspectos emocionais, motores e cognitivos de um indivíduo, que as mídias digitais embora sejam úteis e necessárias para a formação digital do aluno, não pode ser usada de forma que substitua o contato pessoal, familiar, entendendo que os problemas de ordem afetivas são refletidas em sala de aula (SANTOS; MEDINA, 2019)

Já no artigo POLÍTICAS PÚBLICAS DE EDUCAÇÃO: recorte a partir de uma revisão bibliográfica sistemática de Nelson Russo de Moraes, Fernando da Cruz Souza e Caroliny dos Santos Hamada realizam uma Revisão Bibliográfica Sistemática (RBS) na área de políticas públicas educacionais, no Brasil, em sua interface com a desigualdade, com recorte temporal específico 


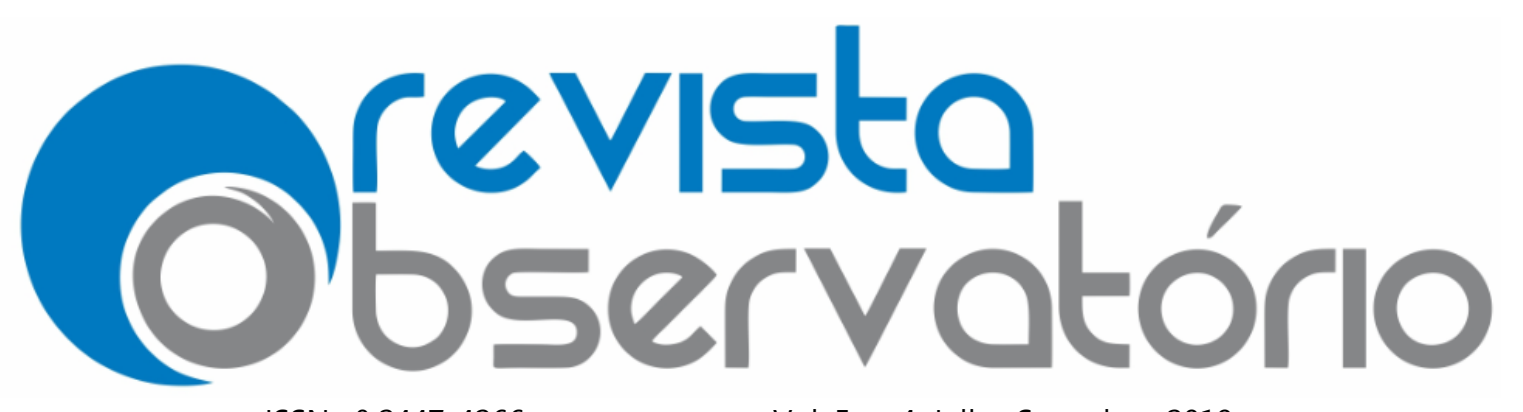

ISSN n² 2447-4266

Vol. 5, n. 4, Julho-Setembro. 2019

DOI: http://dx.doi.org/10.20873/uft.2447-4266.2017v5n4p27

desde a promulgação da CF/88 até os dias atuais. A partir da leitura dos artigos selecionados na RBS, percebe-se que a responsabilidade compartilhada da educação entre os entes subnacionais, os desequilíbrios introduzidos pelo capitalismo, a ausência do fornecimento de um bem-estar mínimo a todos os cidadãos, quando somados aos problemas de desenho e implementação das políticas públicas de educação, levam a produção de conflitos e idiossincrasias que se traduzem na reprodução de desigualdades (MORAES et al., 2019)

E, finalizando os Temas Livres, temos o artigo CULTURA ORGANIZACIONAL: características predominantes (estudo de caso em uma instituição de ensino superior no estado do Tocantins) de Elisabeth Aparecida Corrêa Menezes e Ana Paula Neres Cirqueira identificam a cultura predominante em uma instituição de ensino superior no Estado do Tocantins. No processo de identificação de cultura organizacional, aplicou-se o questionário de Cameron e Quinn (1999) OCAl a uma amostra de 74 pessoas, incluindo corpo docente e administrativo. Os dados da pesquisa revelaram uma grande disparidade entre a cultura atual e a desejável, pois enquanto a cultura atual evidencia que a cultura predominante é a do tipo hierárquica, a desejável vislumbra a do tipo clã, com menos foco em burocracia e controle, para um ambiente mais flexível e dinâmico (MENEZES; CIRQUEIRA, 2019).

Na seção ENSAIO, temos o artigo CULTURA E MEMÓRIA: Fases e Escalas dos Estudos de Memória e o Desafio do Antropoceno de Marcos Palacios estabelece um breve recorrido cronológico e destaca uma divisão em fases dos Estudos de Memória, sugerindo-se que, presentemente, há algo de novo a ser confrontado no âmbito dessa área de pesquisa, exigindo uma inflexão no paradigma ora vigente, ou ao menos seu alargamento. Inicialmente traça-se um breve resumo das diferentes fases de constituição dos Estudos de Memória, enquanto um campo acadêmico específico e multidisciplinar, com ênfase em suas escalas de abrangência: local, nacional e global (PALACIOS, 2019).

$\mathrm{Na}$ seção VISUALIDADES temos o artigo RESIDÊNCIA ARTíSITICA: Cartografias inventivas e o Devir-Planta de Amanda M. P. Leite apresenta resultados da Residência Artística: Cartografias inventivas e o devir-planta, como um desdobramento da pesquisa de Pós-Doutorado realizada no Departamento de Educação, Conhecimento, Linguagem e Arte na Universidade Estadual de Campinas (UNICAMP), sob supervisão de Wenceslao M. de Oliveira Júnior (LEITE, 2019). 


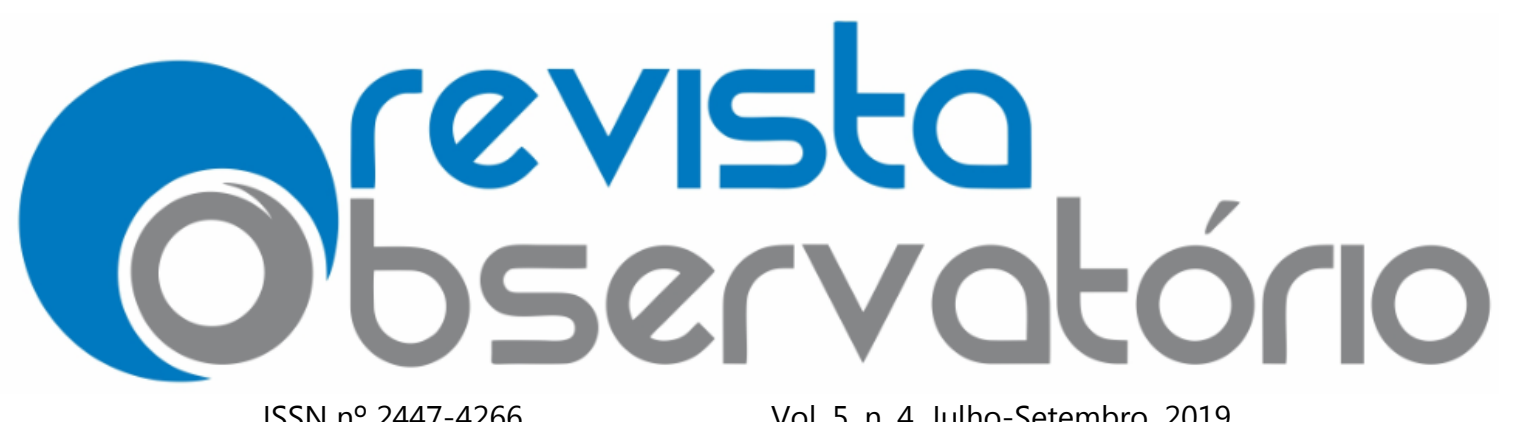

ISSN n² 2447-4266

Vol. 5, n. 4, Julho-Setembro. 2019

DOI: http://dx.doi.org/10.20873/uft.2447-4266.2017v5n4p27

Esperamos que a leitura desse número contribua com as discussões sobre relações possíveis entre comunicação, jornalismo, pesquisa e extensão universitária em diversos ambientes e momentos!

São Paulo-SP, Porto Alegre-RS, Palmas-TO/ Tupã-SP, maio de 2019.

Editores convidados/ Guest Editors/ Editores invitados

Prof. Dr. Duílio Fabbri Júnior, Universidade Federal de São Carlos (UFSCar) / Centro Universitário Salesiano de São Paulo (Unisal)/ Centro Universitário Padre Anchieta (UniAnchieta),

Brasil

Prof. Fabiano Ormaneze, Universidade Estadual de Campinas (Unicamp) / Centro Universitário UniMetrocamp Wyden (UniMetrocamp) / Centro Universitário Padre Anchieta (UniAnchieta),

Brasil

Profa. Dra. Sandra de Deus, Universidade Federal do Rio Grande do Sul (UFRGS), Brasil.

Editor Geral / Chief Editor / Editor general

Prof. Dr. Nelson Russo de Moraes, Universidade Estadual Paulista Júlio de Mesquita Filho (UNESP),

Brasil

Prof. Dr. Francisco Gilson Rebouças Porto Junior, Universidade Federal do Tocantins (UFT), Brasil.

\section{Referências}

ALMEIDA, C. D. DE; OLIVEIRA, S. B.; BRUM, L. S. DA COMUNICAÇÃO NÃO-VIOLENTA À CULTURA DE PAZ: círculos, narrativas e contribuições. Revista Observatório, v. 5, n. 4, p. 463-480, 1 jul. 2019. DOI: https://doi.org/10.20873/uft.2447-4266.2017v5n4p463.

ALVES, M. J. A.; SANTOS, F. M. R. EUFONIA: RADIOJORNALISMO EDUCATIVO NO SEMIÁRIDO. Revista Observatório, $\quad$ v. $\quad 5, \quad$ n. $4, \quad$ p. $63-80, \quad 1$ jul. 2019. DOI: https://doi.org/10.20873/uft.2447-4266.2017v5n4p63. 


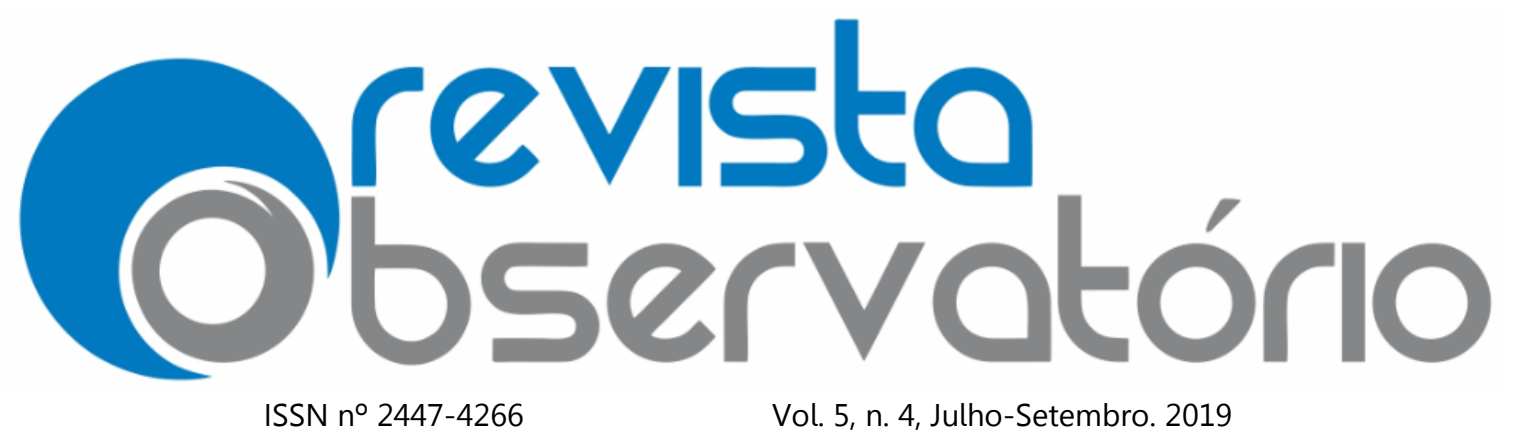

DOI: http://dx.doi.org/10.20873/uft.2447-4266.2017v5n4p27

ALVES, E. J.; SILVA, B. D. DA. APRENDER "COM" A TECNOLOGIA: O uso do Facebook no processo de aprendizagem e interação de curso online. Revista Observatório, v. 5, n. 4, p. 658-669, 1 jul. 2019. DOI: https://doi.org/10.20873/uft.2447-4266.2017v5n4p658.

BERTI, O. M. DE C. EXTENSÃO E QUESTÕES COMUNICACIONAIS SOCIAIS: o caso do curso de Fotografia, Feminismo e Mulheres Diversas da Universidade Estadual do Piauí. Revista Observatório, v. 5, n. 4, p. 258-279, 1 jul. 2019. DOl: https://doi.org/10.20873/uft.24474266.2017v5n4p258.

BRASIL. Ministério da Educação. Conselho Nacional de Educação. Câmera de Educação Superior. Institui as Diretrizes Curriculares Nacionais para o curso de graduação em Jornalismo, bacharelado, e dá outras providências. Resolução CNE/CES nº 1, de 27 de setembro de 2013.

CARVALHO, A. L. P. DE. OS FAZERES JORNALÍSTICO-CULTURAIS DO PROGRAMA DE EXTENSÃO 'PARAÍBA CRIATIVA'. Revista Observatório, v. 5, n. 4, p. 102-126, 1 jul. 2019. DOI: https://doi.org/10.20873/uft.2447-4266.2017v5n4p102.

CANCLINI, N. G. Culturas híbridas: como entrar e sair da modernidade. São Paulo: Edusp, 2001.

CASTANHEIRA, K. N. L.; CONRADO, D. B. F.; BUENO JÚNIOR, E. V. PORTAL CÂMARA VIRTUAL: a participação cidadã no legislativo de frutal. Revista Observatório, v. 5, n. 4, p. 127-147, 1 jul. 2019. DOI: https://doi.org/10.20873/uft.2447-4266.2017v5n4p127.

CORCINI, L. F.; MOSER, A. CIBERESPAÇO, MULTITAREFAS E ATENÇÃO: breve revisão bibliográfica. Revista Observatório, v. $\quad 5$, n. $\quad 4$, p. $309-334,1$ jul. 2019. DOI: https://doi.org/10.20873/uft.2447-4266.2017v5n4p309.

DIAS, R.; LACERDA, E. M.; GOMES, V. M. L. R. JORNALISMO NOS LIMITES DA LIBERDADE: cobertura da imprensa sobre os casos dos religiosos acusados de praticar atividades subversivas durante 0 regime militar. Revista Observatório, v. 5, n. 4, p. 359-411, 1 jul. 2019. DOI: https://doi.org/10.20873/uft.2447-4266.2017v5n4p359.

DUGNANI, P. MEIOS DE COMUNICAÇÃO: Extensão e Alienação. Revista Observatório, v. 5, n. 4, p. 481-501, 1 jul. 2019. DOI: https://doi.org/10.20873/uft.2447-4266.2017v5n4p481.

FABBRI JÚNIOR, D.; ORMANEZE, F. EXTENSÃO E FORMAÇÃO CONTINUADA EM JORNALISMO: A experiência do curso "Gênero, discurso e mídia". Revista Observatório, v. 5, n. 4, p. 237-257, 1 jul. 2019. DOI: https://doi.org/10.20873/uft.2447-4266.2017v5n4p237.

FORPROEX - FÓRUM DE PRÓ-REITORES DE EXTENSÃO DAS UNIVERSIDADES PÚBLICAS BRASILEIRAS. Política Nacional de Extensão Universitária. Manaus, 2012. Disponível em http://proex.ufsc.br/files/2016/04/Pol\%C3\%ADtica-Nacional-de-Extens\%C3\%A3oUniversit\%C3\%A1ria-e-book.pdf. Acesso em: 18 jan. 2019. 


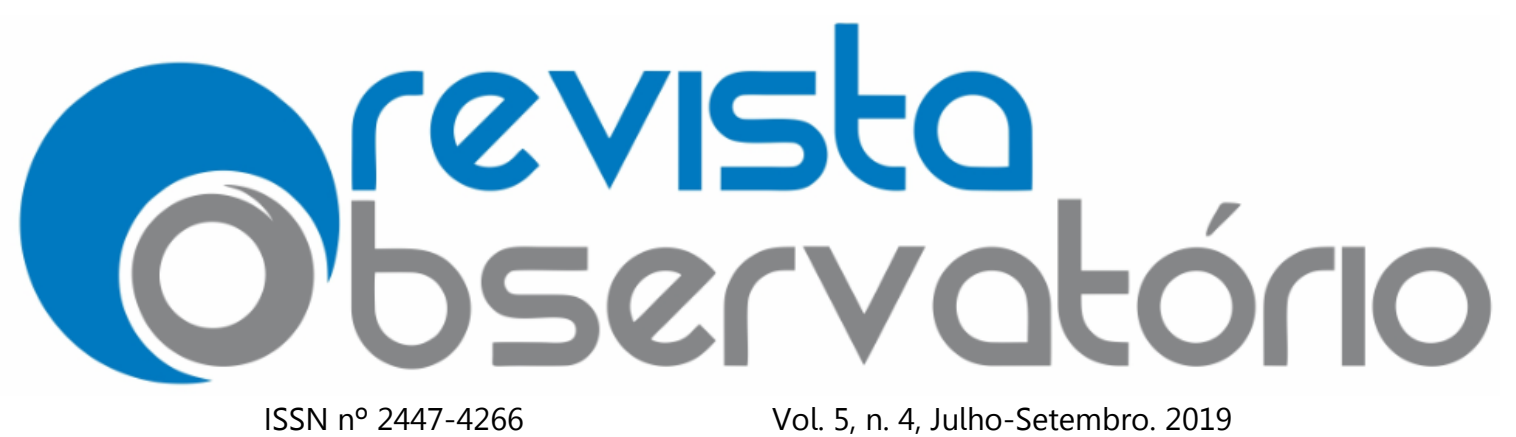

DOI: http://dx.doi.org/10.20873/uft.2447-4266.2017v5n4p27

GAPY, L.; ROVIDA, M.; MARTINEZ, M.; SILVA, P. C. DA. COMUNICALAB: uma ponte entre Sorocaba e as pesquisas em Comunicação da Uniso. Revista Observatório, v. 5, n. 4, p. 166-196, 1 jul. 2019. DOI: https://doi.org/10.20873/uft.2447-4266.2017v5n4p166.

HOLANDA, A. E. G.; BRANDÃO, P. DE M. COMUNICAÇÃO INTEGRADA EM UMA UNIVERSIDADE PÚBLICA: um modelo para análise situacional na perspectiva da teoria da comunicação integrada e da análise de redes sociais. Revista Observatório, v. 5, n. 4, p. 502-524, 1 jul. 2019. DOI: https://doi.org/10.20873/uft.2447-4266.2017v5n4p502.

LEITE, A. M. P. RESIDÊNCIA ARTÍSTICA: Cartografias inventivas e o Devir-Planta. Revista Observatório, v. 5, n. 4, p. 771-776, 1 jul. 2019. DOI: https://doi.org/10.20873/uft.24474266.2017v5n4p771.

LUZ, A. L. L. DA; BOMFIM, I. CONVERGÊNCIA JORNALÍSTICA: Uma revisão de métodos das Dissertações e Teses do banco da Capes (2012-2017). Revista Observatório, v. 5, n. 4, p. 335-358, 1 jul. 2019. DOI: https://doi.org/10.20873/uft.2447-4266.2017v5n4p335.

MARCOS, P. S. M. P. MESTRES DA REPORTAGEM: o livro que virou série em favor de estudantes e da sociedade. Revista Observatório, v. 5, n. 4, p. 223-236, 1 jul. 2019. DOI: https://doi.org/10.20873/uft.2447-4266.2017v5n4p223.

MIGUEL, K. G.; MACHADO, M. F. JORNALISMO E AFETOS NA EXPERIÊNCIA TRANSMÍDIA DO MOVIMENTO AMBIENTAL. Revista Observatório, v. 5, n. 4, p. 280-308, 1 jul. 2019. DOI: https://doi.org/10.20873/uft.2447-4266.2017v5n4p280.

MENEZES, E. A. C.; CIRQUEIRA, A. P. N. CULTURA ORGANIZACIONAL: características predominantes (estudo de caso em uma instituição de ensino superior no estado do Tocantins). Revista Observatório, v. 5, n. 4, p. 710-748, 1 jul. 2019. DOI: https://doi.org/10.20873/uft.24474266.2017v5n4p710.

MORAES, N. R. DE; SOUZA, F. DA C.; HAMADA, C. DOS S. POLÍTICAS PÚBLICAS DE EDUCAÇÃO: recorte a partir de uma revisão bibliográfica sistemática. Revista Observatório, v. 5, n. 4, p. 670709, 1 jul. 2019. DOI: https://doi.org/10.20873/uft.2447-4266.2017v5n4p670.

MUNARO, L. F. NEM INFERNO, NEM PARAÍSO: esfera pública e a construção de um conceito de Amazônia (1930-1937). Revista Observatório, v. 5, n. 4, p. 412-437, 1 jul. 2019. DOI: https://doi.org/10.20873/uft.2447-4266.2017v5n4p412.

YÚDICE, G. A conveniência da cultura: usos da cultura na era global. Belo Horizonte: Editora UFMG, 2004. 


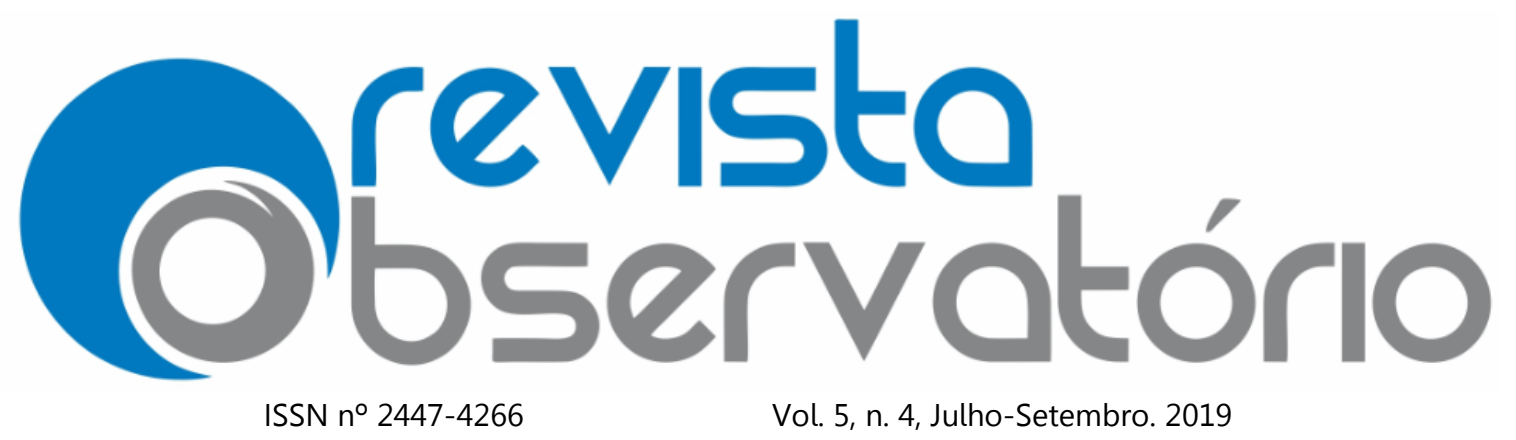

DOI: http://dx.doi.org/10.20873/uft.2447-4266.2017v5n4p27

PALACIOS, M. CULTURA E MEMÓRIA: Fases e Escalas dos Estudos de Memória e o Desafio do Antropoceno. Revista Observatório, v. 5, n. 4, p. 749-770, 1 jul. 2019. DOI: https://doi.org/10.20873/uft.2447-4266.2017v5n4p749.

ROSA, T. F. M.; PEDROSO NETO, A. J. A COBERTURA DO BNDES NOS GOVERNOS FHC E LULA: bases ortodoxas nas narrativas sobre privatizações e PAC. Revista Observatório, v. 5, n. 4, p. 525578, 1 jul. 2019. DOI: https://doi.org/10.20873/uft.2447-4266.2017v5n4p525.

SANTOS, W. DA S.; MEDINA, P. ORFANDADE EMOCIONAL: uma herança refletida nas salas de aula. Revista Observatório, v. 5, n. 4, p. 634-657, 1 jul. 2019. DOI: https://doi.org/10.20873/uft.2447-4266.2017v5n4p634.

SANTOS, A. C. DE M.; PÊSSOA, M. T. R.; CAMPOS, M. DE F. H. METODOLOGIAS DE DIFUSÃO DO CONHECIMENTO NO ENSINO SUPERIOR EAD: contribuições dos MOOCS. Revista Observatório, v. 5, n. 4, p. 579-612, 1 jul. 2019. DOI: https://doi.org/10.20873/uft.2447-4266.2017v5n4p579.

SILVA, F. F. DA; ARAÚJO, A. F. N.; ROCHA, E. DE C. PROJETO REPÓRTER JUNINO E A CONSTRUÇÃO DA MEMÓRIA DOS FESTEJOS JUNINOS EM AMBIÊNCIA DIGITAL: novos formatos, linguagens e saberes em rede. Revista Observatório, v. 5, n. 4, p. 81-101, 1 jul. 2019. DOI: https://doi.org/10.20873/uft.2447-4266.2017v5n4p81.

SILVA, A. M.; RIOS, A. PROJETO RONDON: a experiência da UCB na cobertura jornalística. Revista Observatório, v. 5, n. 4, p. 148-165, 1 jul. 2019. DOI: https://doi.org/10.20873/uft.24474266.2017v5n4p148.

SOUZA, P. C. L. DE. CINECLUBE ESPORTE E SOCIEDADE: cinema, comunicação e entretenimento em um projeto de extensão. Revista Observatório, v. 5, n. 4, p. 197-222, 1 jul. 2019. DOI: https://doi.org/10.20873/uft.2447-4266.2017v5n4p197.

XAVIER, C.; VERNER, A. VALORES-NOTÍCIA E INTERNET: Um estudo exploratório sobre as notícias mais acessadas do portal aRede. Revista Observatório, v. 5, n. 4, p. 438-462, 1 jul. 2019. DOI: https://doi.org/10.20873/uft.2447-4266.2017v5n4p438.

ZACARIOTTI, M. E. C.; SOUSA, J. L. DOS S. TECNOLOGIAS DIGITAIS DE INFORMAÇÃO E COMUNICAÇÃO COMO RECURSO DE MEDIAÇÃO PEDAGÓGICA. Revista Observatório, v. 5, n. 4, p. 613-633, 1 jul. 2019. DOI: https://doi.org/10.20873/uft.2447-4266.2017v5n4p613.

ZUCULOTO, V.; BETTI, J. G.; CLASEN, B. H.; AGUIAR, G. G. DE. A RÁDIO PONTO UFSC NA COBERTURA DAS ELEIÇÕES MUNICIPAIS: uma experiência de extensão articulada com ensino e $\begin{array}{llllllllll}\text { pesquisa. Revista Observatório, } & \text { v. } 5, \quad \text { n. } & 4, & \text { p. } & 39-62, & 1\end{array}$ DOI: https://doi.org/10.20873/uft.2447-4266.2017v5n4p39. 